\title{
Association between increased neutrophil- to-lymphocyte ratio and postoperative delirium in elderly patients with total hip arthroplasty for hip fracture
}

Rui He ${ }^{1}$, Fei Wang ${ }^{2^{*}+}$, Huarui Shen ${ }^{3^{*}+}$, Yong Zeng ${ }^{1}$ and LijuanZhang ${ }^{4}$

\begin{abstract}
Background: Delirium is a common complication in elderly patients with total hip arthroplasty (THA) for hip fracture. The mechanism of postoperative delirium (POD) is associated with the neuroinflammatory process. The aim of this study was to the incidence and perioperative risk factors of POD and investigate whether NLR could serve as a potential marker for POD in elderly patients with THA for hip fracture.

Methods: This was a multicenter prospective study, we included elderly patients with THA for hip fracture under general anesthesia. Receiver operating characteristic (ROC) curve was performed to identify the optimal cut point of NLR for POD. The relationship between NLR and POD was analyzed by multivariable analysis.

Results: Seven hundred eighty patients (mean age $73.33 \pm 7.66$ ) were eligible for inclusion in the study. $23.33 \%$ (182/780) of patients had POD. ROC curve analysis showed that the optimal cut point of NLR for POD was NLR 23.5. Compared with no POD, higher NLR, older age, diabetes, and higher neutrophil count were more likely in patients with $\operatorname{POD}(P<0.05)$. Multivariate logistic regression analysis showed that $N L R \geq 3.50$ [adjusted odds ratio(aOR), 3.93; confidence interval $(\mathrm{Cl}), 2.47-6.25 ; P<0.001)$ ], older age (aOR, 1.04; 95\% Cl, 1.02-1.07; $P=0.001$ ), diabetes $(a O R, 1.58 ; 95 \% \mathrm{Cl}, 1.06-2.36 ; P=0.025)$, higher neutrophil count (aOR, 1.25; 95\%Cl, 1.15-1.35; $P<0.001$ ) were associated with increased risk of POD.
\end{abstract}

Conclusions: Older age, diabetes, higher neutrophil count, and NLR $\geq 3.5$ were independent risk factors for POD, and NLR can be used as a potential marker for prediction of delirium in elderly patients with THA for hip fracture.

Keywords: Total hip arthroplasty, Neutrophil-to-lymphocyte ratio, Postoperative delirium, Elderly patients

\footnotetext{
* Correspondence: 3504185428@qq.com; 2399548051@qq.com

${ }^{\dagger}$ Fei Wang and Huarui Shen contributed equally to this work.

${ }^{2}$ Department of Joint Surgery, The Third People's Hospital of Chengdu,

Chengdu 610000, People's Republic of China

${ }^{3}$ Department of Joint Surgery, Affiliated Traditional Chinese Medical Hospital

of Southwest Medical University of Sichuan Province, Luzhou 646000,

People's Republic of China

Full list of author information is available at the end of the article
}

(C) The Author(s). 2020 Open Access This article is licensed under a Creative Commons Attribution 4.0 International License, which permits use, sharing, adaptation, distribution and reproduction in any medium or format, as long as you give appropriate credit to the original author(s) and the source, provide a link to the Creative Commons licence, and indicate if changes were made. The images or other third party material in this article are included in the article's Creative Commons licence, unless indicated otherwise in a credit line to the material. If material is not included in the article's Creative Commons licence and your intended use is not permitted by statutory regulation or exceeds the permitted use, you will need to obtain permission directly from the copyright holder. To view a copy of this licence, visit http://creativecommons.org/licenses/by/4.0/ The Creative Commons Public Domain Dedication waiver (http://creativecommons.org/publicdomain/zero/1.0/) applies to the data made available in this article, unless otherwise stated in a credit line to the data. 


\section{Background}

Delirium is defined as an acute disorder of attention and cognition, it is a common complication of surgery, especially in elderly patients. Postoperative delirium (POD) is a well-described medical problem with long-term consequences of increased mortality and morbidity [1]. POD usually occurs within 5 days after surgery [2, 3]. Studies have shown that the incidence of POD is between 15.7$48 \%$ in elderly patients with hip fractures [4-6]. POD has a negative effect on postoperative recovery, increases the nursing burden of caregivers, extends the length of hospital stay, increases hospitalization costs and hospitalization mortality, and may even lead to longterm cognitive impairment [7-9]. Its pathogenesis is complex and remains to be clarified.

The pathophysiology of delirium is not fully understood, many disorders of physiological mechanisms may be involved, including neuroinflammation and the effects of oxidative stress $[10,11]$. Considering delirium may be related to the pathological mechanism of inflammation, it is particularly important to find predictive markers in inflammatory factors. The scientific studies showed that certain inflammatory markers are associated with POD $[12,13]$, but they may be excluded in clinical practice due to cost or cumbersome diagnostic procedures. There are relatively few studies devoted to association serum biomarkers with POD [12, 14].

Neutrophil-lymphocyte ratio (NLR) is a marker of inflammation and oxidative stress. Previous study reported that NLR increased in elderly patients with delirium [15]. NLR had been used as a marker of inflammation in cardiovascular disease and diabetes $[16,17]$. A study showed that NLR in peripheral blood can also be used as a simple systemic inflammatory response (SIR) marker and has diagnostic value for some diseases [18]. NLR has been shown to be a good predictor of outcomes for neurological and psychiatric disorders [19-21].

Increased NLR for developing delirium after total hip arthroplasty (THA) in elderly hip fracture patients have not been investigated. We hypothesized that in the elderly hip fracture patients with THA who had POD would be predicted by higher NLR value. Therefore, the current study was undertaken to investigate the incidence and perioperative risk factors of POD and investigate whether NLR could serve as a potential marker for POD in elderly patients with THA for hip fracture.

\section{Methods}

\section{Study population}

This study was a prospective multicenter study conducted in three medical centers: The Second People's Hospital of Chengdu, The Third People's Hospital of Chengdu, Affiliated Traditional Chinese Medical Hospital of Southwest Medical University of Sichuan
Province. The study enrolled elderly patients with THA for hip fracture between March 2014 and December 2019 (registration number: ChiCTR2000037945). Patients were included in the study only if they fulfilled all the following criteria: 1. Aged $\geq 65$ years; 2. Patients underwent the first THA procedure; 3. American Society of Anesthesiologists physical status I-III. The exclusion criteria were the following: 1.Owning infection at admission; 2 Postoperative infections; 3.A history of dementia or Mini-Mental State Examination (MMSE) score < 24; 4. Patients who underwent other surgery within 6 months; 5.A history of mental illness; 6.Cardiac (include acute myocardial infarction, congestive heart failure, a history of tachyarrhythmia/bradyarrhythmia or atrial fibrillation), pulmonary disease and impaired renal function (estimated glomerular filtration rate $<60 \mathrm{~mL} / \mathrm{min}$ per $1.73 \mathrm{~m}^{2}$ ); 7.Using antipsychotic medications; 8.Alcohol or drug abuse; 9.Incapable of appropriate communication;10.Preoperative delirium, stroke after surgery and in-hospital mortality.

\section{Data collection}

We collected all patients' the baseline characteristics within $24 \mathrm{~h}$ after admission and before surgery. Routine laboratory tests were undertaken within $24 \mathrm{~h}$ after admission, including blood counts, blood chemistries, hepatic and renal function, blood glucose. The complete blood cell counts were analyzed using a Sysmex XE5000 instrument (Sysmex, Kobe, Japan). The neutrophil count divided by the lymphocyte count yielded the NLR. CRP was detected with immunoturbidimetric method (Cobas 8000 c701/702 analyzer, Roche Diagnostics, Rotkreuz, Switzerland).

The symptoms and signs of infections were assessed, white blood cell count, procalcitonin (PCT), urine screening, chest $\mathrm{CT}$, and body temperature (at least 3 times a day) were monitored within 7 days after admission. Infections included pulmonary infection, urinary tract infection and other localization's infections were excluded.

To assess mental status, we used the Mini-Mental State Examination (MMSE) as an estimate of preoperative cognitive decline. A score lower than 24 on this scale indicates cognitive decline. Prefracture activities of daily living (ADL) functioning was assessed with the Barthel Index (BI).

Two research nurses trained in delirium assessment and not involved in the clinical care of participants performed all clinical assessments. The diagnostic criteria of delirium are described by the Diagnostic and Statistical Manual IV diagnostic criteria [22] and the Confusion Assessment Method (CAM) [23]. Delirium assessment contains four evaluation features: (i) acute change or fluctuating course of mental status; (ii) inattention; (iii) altered level of consciousness; (iv) disorganized thinking; 
A positive diagnosis of delirium required the presence of items (i) and (ii), and either (iii) or (iv). All patients were assessed for delirium once daily, using the CAM from time of admission to the seventh postoperative day. CAM was applied by two research nurses, based on a 10-30-min interview with the patient, together with information from close relatives, nurses, and hospital records. The CAM has been validated in several languages and replicated in multiple settings.

\section{Statistical analysis}

Patients were classified into no POD and POD groups. The data are presented as numbers (\%) or means ( \pm standard deviations). Receiver operating characteristic (ROC) curve was used to determine the optimal NLR for POD. To identify differences between no POD and POD groups, the Pearson $X^{2}$ test was used for categorical variables. Student's t-test was used to compare normally distributed variables. Mann-Whitney $U$ tests were used to compare nonnormally distributed variables. Multivariate logistic regression analysis was performed to identify determinants independently associated with POD. Variables associated with POD in the univariate analyses with a $P$-value $<0.20$ were included in the multivariate analysis. The results are expressed as the adjusted odds ratio (aOR) with their corresponding 95\% confidence interval $(\mathrm{CI})$. The data were analyzed using SPSS 22 software. $P<0.05$ was considered statistically significant.

\section{Results}

Characteristics of the study subjects

The patients were included for this study from three centers. A total of 1437 patients( $\geq 65$ years) with hip fracture who may undergo THA were included, 27 patients

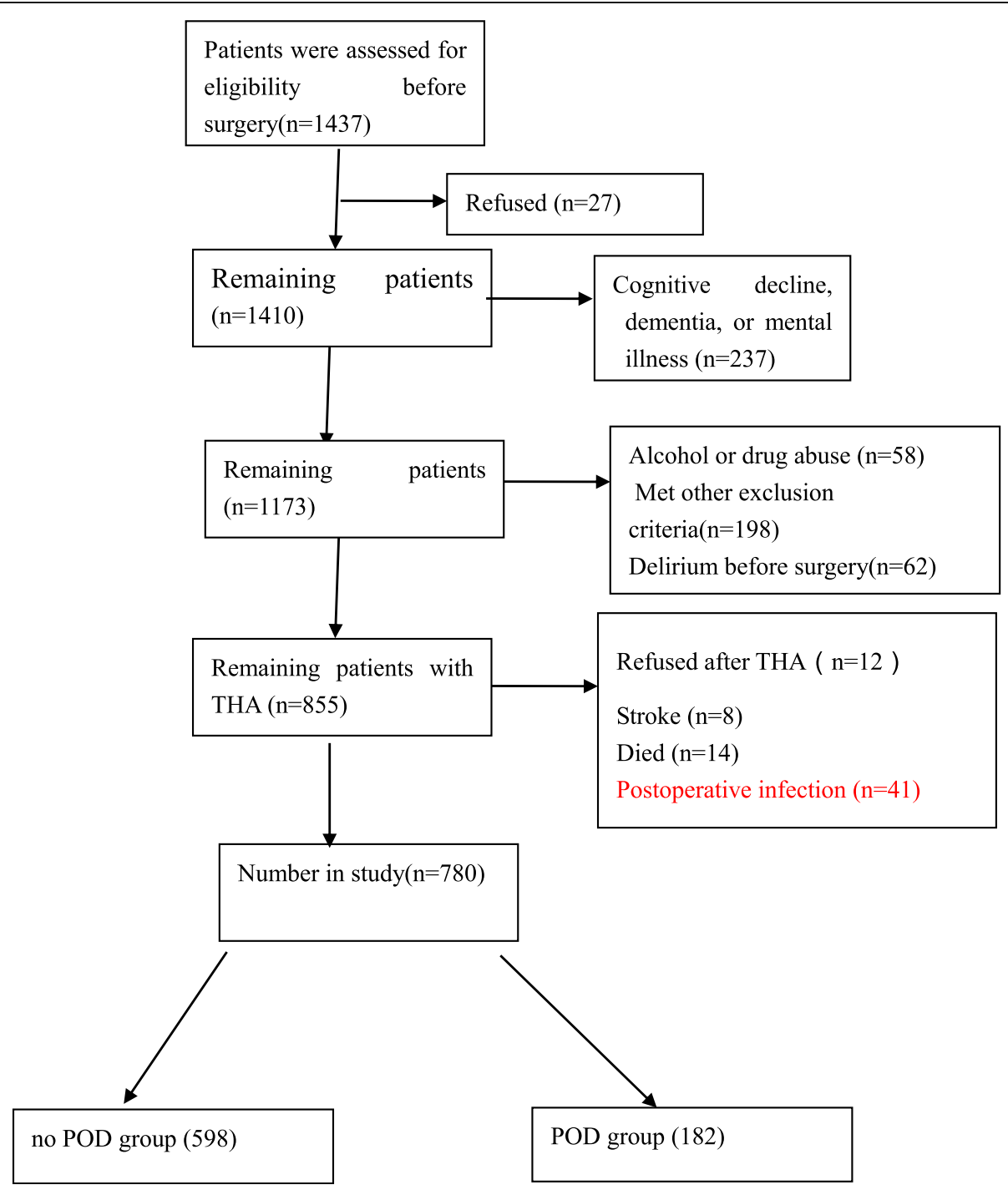

Fig. 1 Patient's flowchart 
refused to participate in the study before THA, 237 patients had cognitive decline, dementia, or mental illness, 58 patients had history of alcohol or drug abuse, and 198 patients were excluded because they met 1 or more of the other exclusion criteria, 62 patients had delirium before surgery. The remaining 855 patients, among them after THA,12 patients refused to participate in the study, 8 patients had stroke, 14 had died, and 41 had infection, the remaining 780 patients were enrolled (Fig. 1), the mean age was $73.33 \pm 7.66$ years (65-97 years), comprised $48.59 \%$ (379) men. In the study population, 527 patients had a history of hypertension, 280 had a history of diabetes, 468 had a history of hyperlipidemia, 214 patients current Smoking. The median Barthel score was 89 points prior hip fracture. The mean Surgery duration was $87.31 \mathrm{~min}$.

182(23.33\%) patients experienced POD, the median hours between surgery and diagnosis of POD was 47.1 (range: 25.7-75.9). Baseline characteristics of patients in the no POD and POD groups were compared (Table 1). At baseline, patients with POD showed significantly older age $(75.77 \pm 8.57$ vs73.28 $\pm 7.44, P<0.001)$, higher NLR value [ $4.67 \pm 1.62$ vs $2.68 \pm 1.26, P<0.001$ ], higher neutrophil count $(6.67 \pm 3.55$ vs $3.77 \pm 2.29, P<0.001)$, higher percentage of diabetes [79(43.41\%) vs201(33.61\%), $P<0.001]$ than patients with no POD.

\section{Evaluation of the prognostic value of NLR for POD}

ROC curve analysis showed high accuracy for NLR to predict POD with AUC of 0.83 (95\% CI 0.80 to 0.86) (Fig. 2). Using a cut off value for NLR $\geq 3.50$, the sensitivity was $74.73 \%$, and the specificity was $73.91 \%$, providing a positive predictive value (PPV) for POD of $46.57 \%$. Compared with patients no POD, those with POD had higher prevalence of NLR $\geq 3.50$ (74.73\% vs $26.09 \%, P<0.001)$.

\section{Multivariable models on the association between NLR $\geq$ 3.50 and POD}

Unadjusted logistic regression analysis identified older age (OR,1.04; 95\%CI,1.02-1.07; $P<0.001)$, percentage of diabetes (OR,1.52; 95\%CI,1.08-2.13; $P=0.016)$, higher neutrophil count (OR,1.43; 95\%CI,1.33-1.53; $P<0.001)$, and higher NLR value (OR,2.78; 95\%CI,2.35-3.29; $P<$ 0.001 ) as factors associated with a risk predictor of POD. When the factors associated with POD in the univariate analyses $(P<0.20)$ were entered into the multivariate logistic regression analysis (adjusted for age, Barthel score, NLR value or NLR $\geq 3.50$, neutrophil count, surgery

Table 1 Comparison of baseline characteristics between patients with no POD and POD groups

\begin{tabular}{|c|c|c|c|c|}
\hline & no POD group (598) & POD group (182) & $\mathrm{OR}(95 \% \mathrm{Cl})$ & $P^{*}$ \\
\hline Age, y (Mean SD) & $73.28 \pm 7.44$ & $75.77 \pm 8.57$ & & $<0.001$ \\
\hline Female, $n(\%)$ & $302(53.40)$ & 99 (46.39) & $1.17(0.84-1.63)$ & 0.357 \\
\hline Male, n(\%) & $296(46.60)$ & $83(53.61)$ & $1.17(0.84-1.63)$ & 0.357 \\
\hline $\mathrm{BMI} \geq 24$ kg/m, n(\%) & $181(28.40)$ & $51(31.96)$ & $0.90(0.62-1.30)$ & 0.562 \\
\hline Current Smoking, $n(\%)$ & $168(25.24)$ & $46(30.41)$ & $0.87(0.59-1.27)$ & 0.455 \\
\hline Hypertension, n(\%) & $404(66.26)$ & $123(60.82)$ & $1.00(0.70-1.43)$ & 0.995 \\
\hline Diabetes, n(\%) & $201(33.61)$ & $79(43.41)$ & $1.52(1.08-2.13)$ & 0.016 \\
\hline Hyperlipidemia, n(\%) & $364(57.52)$ & $104(50.00)$ & $0.86(0.61-1.20)$ & 0.369 \\
\hline Duration of fracture, d (Mean SD) & $10.29 \pm 11.09$ & $9.23 \pm 10.19$ & & 0.302 \\
\hline Admission to operation duration, h (Mean SD) & $61.14 \pm 21.59$ & $59.14 \pm 21.16$ & & 0.283 \\
\hline Surgery duration, (Mean SD) & $79.87 \pm 18.03$ & $82.56 \pm 18.14$ & & 0.077 \\
\hline Anesthesia duration, h (Mean SD) & $99.53 \pm 18.41$ & $102.23 \pm 18.15$ & & 0.088 \\
\hline Barthel score, (Mean SD) & $87.475 \pm 12.20$ & $88.90 \pm 12.32$ & & 0.167 \\
\hline MMSE score, (Mean SD) & $27.63 \pm 1.75$ & $27.36 \pm 1.73$ & & 0.068 \\
\hline Neutrophil count $\left(\times 10^{9} / L\right)$, (Mean SD) & $3.77 \pm 2.29$ & $6.67 \pm 3.55$ & & $<0.001$ \\
\hline Lymphocyte count $\left(\times 10^{9} / L\right)$, (Mean SD) & $1.40 \pm 0.51$ & $1.40 \pm 0.58$ & & 0.917 \\
\hline CRP (mg/L), (Mean SD) & $1.35 \pm 0.50$ & $1.38 \pm 0.54$ & & 0.596 \\
\hline Glucose (mg/dL), (Mean SD) & $136.99 \pm 22.54$ & $138.97 \pm 22.72$ & & 0.402 \\
\hline NLR value, (Mean SD) & $2.68 \pm 1.26$ & $4.67 \pm 1.62$ & & $<0.001$ \\
\hline$N L R \geq 3.50, n(\%)$ & $156(26.09)$ & $136(74.73)$ & $8.38(5.72-12.26)$ & $<0.001$ \\
\hline
\end{tabular}

Bold indicates $P$-values less than 0.05

*Comparison between no POD and POD groups. The data are presented as numbers (\%) or mean values ( \pm standard deviation). The Pearson $X^{2}$ test was used for categorical variables. Student's t-test was used to compare normally distributed variables. Mann-Whitney U tests were used to compare nonnormally distributed variables 


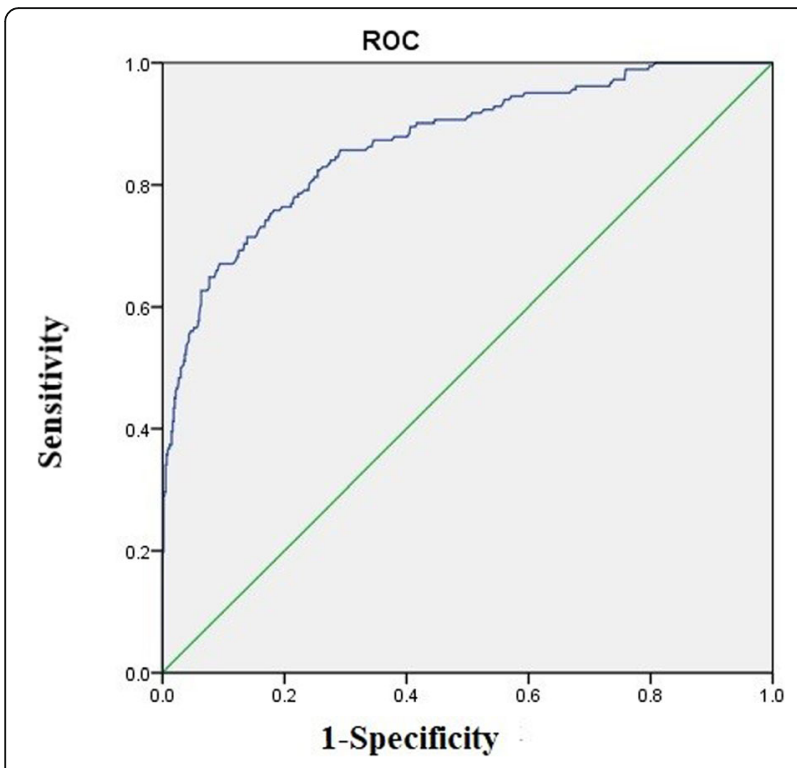

Fig. 2 Receiver operating characteristic curve analysis for NLR for prognostic value for POD

duration, anesthesia duration, MMSE score, diabetes), the results showed that older age (aOR, 1.05; 95\% CI, $1.02-1.07 ; P=0.001$ ), higher NLR value (aOR, 2.74; $95 \%$ CI, 2.20-3.42; $P<0.001$ ), higher neutrophil count (aOR, 1.25; 95\% CI, 1.15-1.35; $P<0.001$ ), and diabetes (aOR, 1.69; 95\% CI, 1.11-2.58; $P=0.015$ ) were associated with increased a risk of POD (Table 2). When NLR $\geq 3.50$ was entered into multivariate logistic regression (Model 2 ), NLR $\geq 3.50$ resulted to be associated with increased risk POD (aOR, 3.93; 95\%CI, 2.47-6.25; $P<0.001$ ), older age (aOR, 1.04; 95\%CI, 1.02-1.07; $P=0.001$ ), diabetes (aOR, 1.58; 95\% CI, 1.06-2.36; $P=0.025$ ) were associated with increased risk POD (Table 2).

Table 2 Multivariable models showing factors associated with POD

\begin{tabular}{lll}
\hline & OR $(\mathbf{9 5} \% \mathbf{C I})$ & $P^{*}$ \\
\hline Model 1(NLR value) & & \\
Older age & $1.05(1.02-1.07)$ & $\mathbf{0 . 0 0 1}$ \\
Higher NLR value & $2.74(2.20-3.42)$ & $<\mathbf{0 . 0 0 1}$ \\
Diabetes & $1.69(1.11-2.58)$ & $\mathbf{0 . 0 1 5}$ \\
Model 2(NLR $\geq 3.50)$ & & \\
Older age & $1.04(1.02-1.07)$ & $\mathbf{0 . 0 0 1}$ \\
Neutrophil count & $1.25(1.15-1.35)$ & $<\mathbf{0 . 0 0 1}$ \\
NLR $\geq 3.50$ & $3.93(2.47-6.25)$ & $<\mathbf{0 . 0 0 1}$ \\
Diabetes & $1.58(1.06-2.36)$ & $\mathbf{0 . 0 2 5}$ \\
\hline
\end{tabular}

Bold indicates $P$-values less than 0.05

*Multivariable adjusted for age, Barthel score, NLR value (NLR $\geq 3.50$ ),

neutrophil count, surgery duration, anesthesia duration, MMSE score, diabetes

\section{Discussion}

In this study, we investigated incidence and perioperative risk factors of POD in order to determine whether pre-existing conditions and NLR would predict the risk of POD. In this study, we found a high incidence of POD in the elderly patients undergoing hip fractures surgery, 182 (23.33\%) elderly patients experienced POD after THA, which was consistent with previous studies [24-26]. ROC curve analysis showed that NLR $\geq 3.5$ was a useful marker for predicting POD, the AUC of 0.83 in POD group further indicated that NLR was predictive of POD with high specificity. We identified risk factors associated with POD. Compared with patients without POD, those with POD were more likely to had older age, diabetes, higher NLR value, higher neutrophil count. Multivariate logistic regression analyses indicated that older age, higher NLR value, diabetes were independent risk factors of POD in elderly patients after THA for hip fracture, elderly patients with NLR $\geq 3.5$ after THA had about 4-fold increased risk of POD.

Delirium is a common and serious complication in elderly patients after surgery because it can lead to decreased function and longer hospital stays [27-30]. Patients with delirium during hospitalization had a higher 6-month mortality rate than those without delirium [31, 32]. Increased morbidity and mortality, longer hospital stays, cognitive and functional decline, and increased institutionalization are all likely to increase social and health care costs $[31,32]$. Our findings have important implications for clinical prevention and early treatment of delirium, NLR is easy to obtain in clinical practice, it is cost-effective.

In the community, the prevalence of delirium among normal elderly people is low (1-2\%), but increases with age, the prevalence increases to $14 \%$ in older people who over 85 years $[33,34]$. The prevalence of delirium is 10 $30 \%$ in older adults who visit the emergency department [35]. The prevalence of delirium is highest among older adults hospitalized. Previous studies have shown that the prevalence of delirium in older patients in the ICU is significantly higher than in younger patients, this finding supports the notion that older age is an important risk factor for delirium [36].

The mechanism of the relationship between age and the POD may be that the ability to respond to stress and adapt to abnormal metabolism was reduced in older patients, and this dysfunction was accompanied by decreased brain volume and decreased physical activity [37]. In addition, with the increase of age, the disorder of various neurotransmitter systems may be the main pathological cause of POD [38].

In this study, we found that diabetes was associated with about 1.6-fold higher risk of POD. Possible causes of POD include cerebral perfusion injury during surgery 
[39], persistent neurotoxic effects after anesthesia, and perioperative opioid use, all of which have negative effect on brain function [40,41]. Diabetic patients generally present with brain microvascular lesions [42, 43] and large vascular injury [44]. Compared with non-diabetic patients, the risk of delirium is increased in diabetic patients $[45,46]$. A previous observational study found that surgery in diabetic patients may accelerate the negative effects of high blood sugar on brain function. Other factors associated with delirium include an up-regulation of sympathetic tone and a down-regulation of parasympathetic tone due to surgical stress, impaired cholinergic function, reversible damage to brain oxidative metabolism, abnormal neurotransmitter pathways, and the release of neuroinflammation [47]. Hyperglycemia is a known factor inducing neuroinflammation and a physiological response to inflammation and is also an important cause of delirium in diabetic patients.

Under pathological conditions, the relationship between NLR and delirium has not been clarified. A recent study had found that NLR can be a predictive factor for delirium after acute ischemic stroke [48]. The data regarding the NLR in POD had not been studied previously. In the present study, we found that increased NLR was an independent risk factor for developing POD in hip fracture patients with THA. The NLR was elevated in POD group $(4.67 \pm 1.62$ vs. $2.68 \pm 1.26, P<$ 0.001 ), yet AUC for NLR was 0.83 , indicating higher predictive ability. Even at the optimal cut-off of 3.50, the sensitivity was $74.73 \%$ and specificity was $73.91 \%$, making it an ideal test for the detection of POD in elderly patient with THA for hip fracture. This study showed that higher NLR value was associated with a 2.74 -fold higher risk of POD, when NLR $\geq 3.5$ used for predicting POD, we found that NLR $\geq 3.5$ could be an independent risk factor for POD. Our investigation added an important evidence on the relationship between delirium and a dysfunction of immune effector cells. This study found that the immune system and oxidative stress may play an important role in the pathogenesis of POD. Previous studies have shown that inflammatory markers and cytokines can be detected in the cerebrospinal fluid of patients with delirium [49-51]. A growing evidence suggests that neutrophils and lymphocytes are major contributors to acute inflammation [52]. The generalized stress can lead to nonspecific activation of the immune system, increasing the neutrophil count and decreasing the lymphocyte count $[52,53]$. Neutrophils were once activated, they release reactive oxygen species, myeloperoxidase, and proteolytic enzymes [53, 54], which disrupted the blood-brain barrier (BBB) and damaged brain [55]. Decreased lymphocytes, increased levels of catecholamine and cortisol, redistribution of lymphocytes to lymphatic tissue, and accelerated apoptosis, combined the stress of the surgery might lead to a detrimental inflammatory state, which might be underlying mechanisms for delirium $[55,56]$.

Some limitations of this study are worth considering. First, we relied on a single baseline NLR value, lack of dynamic change of NLR, which may provide additional information about development for delirium. Second, we lacked data on APACHE scores, post-operative features that may have affected the outcomes we studied, such as plasma albumin levels, hemoglobin levels, duration spent in intensive care unit, care level, postoperative rehabilitation. Third, we did not evaluate the duration of delirium. Fourth, we did not distinguish between hyperactive versus hypoactive delirium. Fifth, patients with dementia or MMSE score $<24$ were excluded, which limits the generalizability of the results. Despite these limitations, our study is a multicenter clinical study, included the large number of patients, the collection of several important clinical data, the adjustment of data analyses for a wide variety of confounding factors. In addition, it is the first study to evaluate the association between NLR and POD among elderly patients with THA for hip fracture.

\section{Conclusions}

In conclusion, we evaluated found that older age, diabetes, and NLR value were independent risk factors for POD in elderly patients with THA for hip fractures, and NLR can be used as a potential marker for prediction of POD after hip surgery.

\section{Abbreviations \\ Cl: Confidence interval; M: Mean; OR: Odds ratio; SD: Standard deviation; POD: Postoperative delirium; NLR: Neutrophil-to-lymphocyte ratio; THA: Total hip arthroplasty}

\section{Acknowledgments}

We thank all patients and their families for generously consenting to use of human tissues in this research.

\section{Authors' contributions}

$\mathrm{RH}$ was responsible for the concept and design of the study, data collection and analysis and the first draft of the paper and final manuscript. FW and HS were responsible for the data collection the data analysis and interpretation. YZ was responsible for overseeing the concept and design of the study. $L$ was responsible for the data analysis and interpretation. All authors read and approved the final manuscript for publication.

\section{Funding}

No funding source for this work.

\section{Availability of data and materials}

The datasets used and/or analyzed during the current study are available from the corresponding author on reasonable request.

\section{Ethics approval and consent to participate}

We obtained ethical approval for this study from the Medical and Health Research Ethics Committee in The Second People's Hospital of Chengdu, The Third People's Hospital of Chengdu, Affiliated Traditional Chinese Medical Hospital of Southwest Medical University of Sichuan Province. The current study was carried out according to the Declaration of Helsinki. Prior to enrollment, all patients or their legal proxies will be given detailed 
information about the aims, scope and possible consequences of the trial by a physician. No diagnostic or interventional procedures required for the clinical trial. Written informed consent was obtained from all study participants.

\section{Consent for publication}

Not applicable.

\section{Competing interests}

The authors declare that they have no competing interests.

\section{Author details}

'Department of Joint Surgery, The Second People's Hospital of Chengdu, Chengdu 610021, People's Republic of China. ${ }^{2}$ Department of Joint Surgery, The Third People's Hospital of Chengdu, Chengdu 610000, People's Republic of China. ${ }^{3}$ Department of Joint Surgery, Affiliated Traditional Chinese Medical Hospital of Southwest Medical University of Sichuan Province, Luzhou 646000, People's Republic of China. ${ }^{4}$ Department of Neurology, The Second Affiliated Hospital of Chengdu College, Nuclear Industry 416 Hospital, Chengdu 610051, People's Republic of China.

\section{Received: 8 June 2020 Accepted: 30 September 2020}

\section{Published online: 07 October 2020}

\section{References}

1. Yang $Q$, Wang J, Huang $X, X u Y$, Zhang $Y$. Incidence and risk factors associated with postoperative delirium following primary elective total hip arthroplasty: a retrospective nationwide inpatient sample database study. BMC Psychiatry. 2020;20(1):343. https://doi.org/10.1186/s12888-020-02742-6.

2. Silverstein $\mathrm{JH}$, Timberger $\mathrm{M}$, Reich DL, Uysal S. Central nervous system dysfunction after noncardiac surgery and anesthesia in the elderly. Anesthesiology. 2007;106(3):622-8. https://doi.org/10.1097/00000542200703000-00026.

3. Minden SL, Carbone LA, Barsky A, Borus JF, Fife A, Fricchione GL, Orav EJ. Predictors and outcomes of delirium. Gen Hosp Psychiatry. 2005;27(3):20914. https://doi.org/10.1016/j.genhosppsych.2004.12.004.

4. Poeran J, Cozowicz C, Zubizarreta N, Weinstein SM, Deiner SG, Leipzig RM, Friedman JI, Liu J, Mazumdar M, Memtsoudis SG. Modifiable factors associated with postoperative delirium after hip fracture repair: an agestratified retrospective cohort study. Eur J Anaesthesiol. 2020;37(8):649-58. https://doi.org/10.1097/EJA.0000000000001197.

5. Wang NY, Hirao A and Sieber F. Association between intraoperative blood pressure and postoperative delirium in elderly hip fracture patients. PLoS One. 2015;10(4):e0123892. https://doi.org/10.1371/journal.pone.0123892.

6. Zywiel MG, Hurley RT, Perruccio AV, Hancock-Howard RL, Coyte PC, Rampersaud YR. Health economic implications of perioperative delirium in older patients after surgery for a fragility hip fracture. J Bone Joint Surg Am. 2015:97(10):829-36. https://doi.org/10.2106/JBJS.N.00724.

7. Neuman MD, Rosenbaum PR, Ludwig JM, Zubizarreta JR, Silber JH. Anesthesia technique, mortality, and length of stay after hip fracture surgery. JAMA. 2014;311(24):2508-17. https://doi.org/10.1001/jama.2014. 6499.

8. Rizk P, Morris W, Oladeji P, Huo M. Review of postoperative delirium in geriatric patients undergoing hip surgery. GeriatrOrthop Surg Rehabil. 2016; 7(2):100-5. https://doi.org/10.1177/2151458516641162.

9. Basques BA, Bohl DD, Golinvaux NS, Leslie MP, Baumgaertner MR, Grauer JN. Postoperative length of stay and 30-day readmission after geriatric hip fracture: an analysis of 8434 patients. J Orthop Trauma. 2015;29(3):e115-20. https://doi.org/10.1097/BOT.0000000000000222.

10. Zaal IJ, Slooter AJ. Delirium in critically ill patients: epidemiology, pathophysiology, diagnosis, and management. Drugs. 2012;72(11):1457-71. https://doi.org/10.2165/11635520-000000000-00000.

11. Maldonado JR. Neuropathogenesis of delirium: review of current etiologic theories and common pathways. Am J Geriatr Psychiatry. 2013;21(12):1190222. https://doi.org/10.1016/j.jagp.2013.09.005.

12. Beloosesky Y, Hendel D, Weiss A, Hershkovitz A, Grinblat J, Pirotsky A, Barak V. Cytokines and C-reactive protein production in hip-fracture-operated elderly patients. J Gerontol A Biol Sci Med Sci. 2007;62(4):420-6. https://doi. org/10.1093/gerona/62.4.420.

13. Neerland BE, Hall RJ, Seljeflot I, Frihagen F, MacLullich AM, Raeder J, Wyller TB, Watne LO. Associations between delirium and preoperative cerebrospinal fluid C-reactive protein, interleukin-6, and interleukin-6 receptor in individuals with acute hip fracture. J Am Geriatr Soc. 2016;64(7): 1456-63. https://doi.org/10.1111/jgs.14238.

14. Slor CJ, Witlox J, Adamis D, Jansen RWMM, Houdijk APJ, van Gool WA, de Jonghe JFM, Eikelenboom $P$.The trajectory of C-reactive protein serum levels in older hip fracture patients with postoperative delirium. Int J Geriatr Psychiatry. 2019;34(10):1438-46. https://doi.org/10.1002/gps.5139.

15. Egberts A, Mattace-Raso FUS. Increased neutrophil-lymphocyte ratio in delirium: a pilot study. Clin Interv Aging. 2017;12:1115-21. https://doi.org/10 2147/CIA.S137182

16. Bonaventura A, Liberale L, Carbone F, Vecchié A, Bonomi A, Scopinaro N, Camerini GB, Papadia FS, Maggi D, Cordera R, Dallegri F, Adami G, Montecucco F. Baseline neutrophil-to-lymphocyte ratio is associated with long-term T2D remission after metabolic surgery. Acta Diabetol. 2019;56(7): 741-8. https://doi.org/10.1007/s00592-019-01345-2.

17. Halazun HJ, Mergeche IL, Mallon KA, Connolly ES, Heyer EJ. Neutrophil-lymphocyte ratio as a predictor of cognitive dysfunction in carotid endarterectomy patients. J Vasc Surg. 2014;59(3):768-73. https://doi.org/10.1016/j.jvs.2013.08.095.

18. Celikbilek M, Dogan S, Ozbakır O, Zararsız G, Kücük H, Gürsoy S, Yurci A, Güven K, Yücesoy M. Neutrophil-lymphocyte ratio as a predictor of disease severity in ulcerative colitis. J Clin Lab Anal. 2013;27(1):72-6. https://doi.org/ 10.1002/jcla.21564

19. Kulaksizoglu B, Kulaksizoglu S. Relationship between neutrophil/lymphocyte ratio with oxidative stress and psychopathology in patients with schizophrenia. Neuropsychiatr Dis Treat. 2016;12:1999-2005. https://doi.org/ 10.2147/NDT.S110484

20. Yesil Y, Halil M, Ulger Z, Cankurtaran M, Kuyumcu M, Öztürk Z, Kizilarslanoğlu C, Etgül S, Arıoğul S. The evaluation of neutrophillymphocyte ratio in Alzheimer's disease. Dement Geriatr Cogn Disord. 2012; 34(2):69-74. https://doi.org/10.1159/000341583.

21. Xue J, Huang W, Chen X, Li Q, Cai Z, Yu T, Shao B. Neutrophil-to lymphocyte ratio is a prognostic marker in acute ischemic stroke. J Stroke CerebrovascDis. 2017;26(3):650-7. https://doi.org/10.1016/j. jstrokecerebrovasdis.2016.11.010.

22. Widiger TA, Frances AJ, Pincus HA, et al. Diagnostic and statistical manual of mental disorders: DSM-IV. 4th ed. Washington, DC: American Psychiatric Association; 2000

23. Inouye SK, van Dyck CH, Alessi CA, et al. Clarifying confusion: the confusion assessment method. A new method for detection of delirium. Ann Intern Med. 1990;113:941-8.

24. Rizk P, Morris W, Oladeji P, Huo M. Review of postoperative delirium in geriatricpatients undergoing hip surgery. Geriatr Orthop Surg Rehabil. 2016; 7(2):100-5. https://doi.org/10.1177/2151458516641162.

25. Inouye SK, Westendorp RG, Saczynski JS. Delirium in the elderly. Lancet. 2014;383(9920):911-22. https://doi.org/10.1016/S0140-6736(13)60688-1.

26. Berian JR, Zhou L, Russell MM, Hornor MA, Cohen ME, Finlayson E, Ko CY, Rosenthal RA, Robinson TN. Postoperative delirium as a target for surgical quality improvement. Ann Surg. 2018;268(1):93-9. https://doi.org/10.1097/ SLA.0000000000002436.

27. Zenilman ME Delirium an important postoperative complication. JAMA. 2017:317(1):77-8. https://doi.org/10.1001/jama.2016.18174.

28. Wass S, Webster PJ, Nair BR. Delirium in the elderly: a review. Oman Med J. 2008:23(3):150-7. PMID: 22359704.

29. Brauer C, Morrison RS, Silberzweig SB, Siu AL. The cause of delirium in patients with hip fracture. Arch Intern Med. 2000;160(12):1856-60. https:// doi.org/10.1001/archinte.160.12.1856.

30. Freter SH, Dunbar MJ, MacLeod H, Morrison M, Macknight C, Rockwood K. Predicting post-operative delirium in elective orthopaedic patients: the delirium elderly at-risk (DEAR) instrument. Age Ageing. 2005;34(2):169-71. https://doi.org/10.1093/ageing/afh245.

31. Flinn DR, Diehl KM, Seyfried LS, Malani PN. Prevention, diagnosis, and management of postoperative delirium in older adults. J Am Coll Surg. 2009;209(2):261-8. https://doi.org/10.1016/j.jamcollsurg.2009.03.008.

32. Kagansky N, Rimon E, Naor S, Dvornikov E, Cojocaru L, Levy S. Low incidence of delirium in very old patients after surgery for hip fractures. Am J Geriatr Psychiatry. 2004;12(3):306-14. PMID: 15126232.

33. Khurana V, Gambhir IS, Kishore D. Evaluation of delirium in elderly: a hospital-based study. Geriatr Gerontol Int. 2011;11(4):467-73. https://doi.org/ 10.1111/j.1447-0594.2011.00710.x.

34. Marcantonio ER. Delirium in Hospitalized Older Adults. N Engl J Med. 2017; 377(15):1456-66. https://doi.org/10.1056/NEJMcp1605501. 
35. Sharma A, Malhotra S, Grover S, Jindal SK. Incidence, prevalence, risk factor and outcome of delirium in intensive care unit: a study from India. Gen Hosp Psychiatry. 2012;34(6):639-46. https://doi.org/10.1016/j.genhosppsych. 2012.06.009.

36. Lahariya S, Grover S, Bagga S, Sharma A. Delirium in patients admitted to a cardiac intensive care unit with cardiac emergencies in a developing country: incidence, prevalence, risk factor and outcome. Gen Hosp Psychiatry. 2014;36(2):156-64. https://doi.org/10.1016/j.genhosppsych.2013. 10.010 .

37. Shi C, Yang C, Gao R, Yuan W. Risk Factors for Delirium Afer Spinal Surgery: A Meta-Analysis. World Neurosurg. 2015;84(5):1466-72. https://doi.org/10. 1016/j.wneu.2015.05.057.

38. Silverstein $\mathrm{JH}$, Timberger M, Reich DL, Uysal S. Central nervous system dysfunction after noncardiac surgery and anesthesia inthe elderly. Anesthesiology. 2007;106(3):622-8. https://doi.org/10.1097/00000542200703000-00026.

39. Siepe M, Pfeiffer T, Gieringer A, Zemann S, Benk C, Schlensak C, Beyersdorf $F$. Increased systemic perfusion pressure during cardiopulmonary bypass is associated with less early postoperative cognitive dysfunction and delirium. Eur J Cardiothorac Surg. 2011;40(1):200-7. https://doi.org/10.1016/j.ejcts. 2010.11.024.

40. Xie Z, Dong Y, Maeda U, Moir R, Inouye SK, Culley DJ, Crosby G, Tanzi RE. Isoflurane-induced apoptosis: a potential pathogenic link between delirium and dementia. J Gerontol A Biol Sci Med Sci. 2006;61(12):1300-6. https://doi. org/10.1093/gerona/61.12.1300.

41. Krenk L, Rasmussen LS, Kehlet H. New insights into the pathophysiology of postoperative cognitive dysfunction. Acta Anaesthesiol Scand. 2010;54(8): 951-6. https://doi.org/10.1111/j.1399-6576.2010.02268.x.

42. Fülesdi B, Limburg M, Bereczki D, Káplár M, Molnár C, Kappelmayer J, Neuwirth G, CsibaL. Cerebrovascular reactivity and reserve capacity in type II diabetes mellitus. J Diabetes Complicat. 1999;13(4):191-9. https://doi.org/10. 1016/s1056-8727(99)00044-6.

43. Fülesdi B, Limburg M, Bereczki D, Michels RP, Neuwirth G, Legemate D, Valikovics A, Csiba L. Impairment of cerebrovascular reactivity in long-term type 1 diabetes. Diabetes. 1997;46(11):1840-1845. https://doi.org/10.2337/ diab.46.11.1840.

44. van Harten B, de Leeuw FE, Weinstein HC, Scheltens P, Biessels GJ. Brain imaging in patients with diabetes: a systematic review. Diabetes Care. 2006; 29(11):2539-48. https://doi.org/10.2337/dc06-1637.

45. Chatterjee S, Peters SA, Woodward M, Mejia Arango S, Batty GD, Beckett N, Beiser A, Borenstein AR, Crane PK, Haan M, Hassing LB, Hayden KM, Kiyohara Y, Larson EB, Li CY, Ninomiya T, Ohara T, Peters R, Russ TC, Seshadri S, Strand BH, Walker R, Xu W, Huxley RR. Type 2 diabetes as a risk factor for dementia in women compared with men: a pooled analysis of 2.3 million people compromising more than 100,000 cases of dementia. Diabetes Care. 2016;39(2):300-7. https://doi.org/10.2337/dc15-1588.

46. Strachan MW, Reynolds RM, Marioni RE, Price JF. Cognitive function, dementia and type 2 diabetes mellitus in the elderly. Nat Rev Endocrinol. 2011;7(2):108-114. https://doi.org/10.1038/nrendo.2010.228.

47. Adamis D, Treloar A, Martin FC, Gregson N, Hamilton G, Macdonald AJ. APOE and cytokines as biological markers for recovery of prevalent delirium in elderly medical inpatients. Int J Geriatr Psychiatry. 2007;22(7):688-94. https://doi.org/10.1002/gps.1732.

48. Kotfis K, Bott-Olejnik M, Szylińska A, Rotter I. Could neutrophil-tolymphocyte ratio (NLR) serve as a potential marker for delirium prediction in patients with acute ischemic stroke? A prospective observational study. J Clin Med. 2019;8(7):1075. https://doi.org/10.3390/jcm8071075.

49. MacLullich AM, Edelshain BT, Hall RJ, De Vries A, Howie SE, Pearson A, Middleton SD, Gillies F, Armstrong I, White TO. Cerebrospinal fluid interleukin-8 levels are higher in people with hip fracture with perioperative delirium than in controls. J Am Geriatr Soc Actions. 2011;59(6):1151-3. https://doi.org/10.1111/j.1532-5415.2011.03428.x.

50. Egberts A, Wijnbeld EH, Fekkes D, van der Ploeg MA, Ziere G, Hooijkaas H, van der Cammen TJ, Mattace-Raso FU.Neopterin: a potential biomarker for delirium in elderly patients. Dement Geriatr Cogn Disord. 2015;39(1-2):116-24. https://doi.org/10.1159/000366410.

51. Hall RJ, Watne LO, Idland AV, Raeder J, Frihagen F, MacLullich AM, Staff AC, Wyller TB, Fekkes D. Cerebrospinal fluid levels of neopterin are elevated in delirium after hip fracture. J Neuroinflamm. 2016;13(1):170. https://doi.org/ 10.1186/s12974-016-0636-1.
52. Dhabhar FS, Malarkey WB, Neri E, McEwen BS. Stress-induced redistribution of immune cells from barracks to boulevards to battlefields: a tale of three hormones Curt Richter award winner. Psychoneuroendocrinology. 2012; 37(9):1345-1368. https://doi.org/10.1016/j.psyneuen.2012.05.008.

53. Kolaczkowska E. Kubes P. Neutrophil recruitment and function in health and inflammation. Nat Rev Immunol. 2013;13(3):159-175. https://doi.org/10. 1038/nri3399.

54. Schmidt EP, Lee WL, Zemans RL, Yamashita C, Downey GP. On, around, and through: neutrophil-endothelial interactions in innate immunity. Physiology (Bethesda). 2011;26(5):334-347. https://doi.org/10.1152/physiol.00011.2011.

55. Dhabhar FS, McEwen BS. Acute stress enhances while chronic stress suppresses cell-mediated immunity in vivo: a potential role for leukocyte trafficking. Brain Behav Immun. 1997;11(4):286-306. https://doi.org/10.1006/ brbi.1997.0508.

56. Heffernan DS, Monaghan SF, Thakkar RK, Machan JT, Cioffi WG, Ayala A. Failure to normalize lymphopenia following trauma is associated with increased mortality, independent of the leukocytosis pattern. Crit Care. 2012; 16(1):R12. https://doi.org/10.1186/cc11157.

\section{Publisher's Note}

Springer Nature remains neutral with regard to jurisdictional claims in published maps and institutional affiliations.
Ready to submit your research? Choose BMC and benefit from:

- fast, convenient online submission

- thorough peer review by experienced researchers in your field

- rapid publication on acceptance

- support for research data, including large and complex data types

- gold Open Access which fosters wider collaboration and increased citations

- maximum visibility for your research: over $100 \mathrm{M}$ website views per year

At BMC, research is always in progress.

Learn more biomedcentral.com/submissions 